\title{
Separation of ternary sodium chloride/Reactive Black-5 aqueous solutions using two different modules in a nanofiltration pilot plant
}

\author{
T. M. Patel $\cdot$ K. Nath
}

Received: 29 September 2012/Revised: 11 March 2013/Accepted: 17 March 2013/Published online: 16 April 2013

(C) Islamic Azad University (IAU) 2013

\begin{abstract}
Nanofiltration of ternary mixtures of sodium chloride and aqueous solutions of Reactive Black-5 was studied in two different modules, namely, flat sheet and spiral wound over a wide range of operating conditions. Hydrophilized polyamide membrane with molecular weight cutoff of 150 was used for the experiments. Combined effect of dye and salt concentration, trans-membrane pressure drop, initial $\mathrm{pH}$ of feed solution on the permeate flux, and observed retention were investigated. Extent of color removal, chemical oxygen demand (COD), total dissolved solid (TDS), and conductivity were determined to assess performance of the membrane. The experimental results showed that both the permeate flux and observed retention decreased with increase in dye as well as salt concentration in the feed. Permeate fluxes were lower at higher $\mathrm{pH}$ values. Substantial removal of color was achieved in the nanofiltration experiments with a marked reduction in COD and TDS. The process allowed the production of permeate stream with great reutilization possibilities.
\end{abstract}

Keywords Membrane - Salt rejection - Permeate · Chemical oxygen demand $\cdot \mathrm{pH} \cdot$ Transmembrane pressure

\section{Introduction}

Considering both concentration and composition, dye-house effluents generated from the textile industry are among the

T. M. Patel · K. Nath $(\square)$

Department of Chemical Engineering, G H Patel College

of Engineering \& Technology,

Vallabh Vidyanagar 388120, Gujarat, India

e-mail: kaushiknath2003@yahoo.co.in most polluting of the industrial sectors and have been considered a significant environmental concern for several decades. Reactive dyes are soluble anionic dyes that contain one or more reactive groups capable of forming a covalent bond with the hydroxyl groups in the fiber and are not suitable for recycling (Erswell et al. 1988). These dyes have low fixation rates with the highest loss in the effluent compared with other dye types. Besides having strong color, effluents from dye houses contain high concentration of auxiliary chemicals - predominantly inorganic salts, used to regulate the rate of dye fixing on the textile. During the conventional chemical synthesis of dye by precipitation-filtration-drying method the dye is precipitated from an aqueous solution by salt, whereby the final product contains up to $30 \%$ residual salt impurities (He et al. 2009; Yu et al. 2010). Given the great variety of fibers, dyes, and process additives in use, the conventional wastewater treatment of the textile effluent has limited application since the containing pollutants have very high complexity and diversity combined with very low biodegradability (Forgacs et al. 2004).

In order to overcome the disadvantages encountered in the conventional treatment processes for dye wastewater, constant research efforts are put up to look for alternative treatment methods. Membrane-based separation processes, which were the focus of attention of the separation technologists for the past three decades, have the potential to offer an improved separation and several cost advantages over these more traditional techniques. Various works have reported the use of nanofiltration (NF) membranes for dye separations either for wastewater treatment (Nataraj et al. 2009; Mo et al. 2008; Yu et al. 2010; Uzal et al. 2010) or process applications (Levenstein et al. 1996). NF is becoming widely accepted in the dye-house wastewater treatment. Their separation mechanisms involve both steric (sieving) and electrical (Donnan) effects. This combination allows NF 
membranes to be effective for a range of separations of mixtures of organic species (neutral or charged) and salts having molecular weight (200-1,000 g/mol). NF offers a bright possibility of treating not only dye-house effluent but also to make the effluent suitable for recycling, thereby conserving precious fresh water reserves. In NF, salt (as $\mathrm{NaCl}$ ) can easily pass through the membrane skin. The saltrich permeate thus generated from NF can be reused in the preparation of dye baths used in textile industries. Erswell et al. (1988) were one of the first to investigate the prospect of a charged membrane for the reuse of reactive dye liquors. Membrane performance was monitored in terms of dye and salt retention and permeates flux, under varying conditions. Van der Bruggen et al. (2001) examined the mechanisms of retention and flux decline of NF membranes using a synthetic dye bath. Avlonitis et al. (2008) demonstrated that NF treatment of simulated cotton dye effluents was capable of complete color removal, $72 \%$ salt removal, and recycle of $90 \%$ of the water from the original waste stream. Koyuncu et al. (2004) reported similar findings for an actual remazol dye bath wastewater and concluded that inclusion of an NF treatment plant would have a capital expenditure payback period of less than 2 years. Koyuncu and Topacik (2002) studied the effect of dye concentrations on the salt rejection in a cross-flow nanofiltration membrane wherein a model was developed that assumed the presence of a gel layer formed by the dye and the model also included the effects of salt concentration polarization.

Use of different membrane modules for the treatment of same feed solution is the primary route for a designer to achieve the required quantity and quality of the permeate. Keeping this in mind, the objective of the present study was to evaluate the combined effect of dye and salt concentrations, initial feed $\mathrm{pH}$ and feed pressure on permeate flux, salt retention, and permeate quality in reactive dye/salt mixtures by nanofiltration membranes using flat sheet and spiral would modules. Reactive Black-5 and sodium chloride, in different proportions, were used in the experiments. In addition, the fouling index of the membrane and specific energy consumption (SEC) of the high-pressure pump were determined under standardized laboratory conditions.

This work was carried out at the Department of chemical engineering, G H Patel College of Engineering \& Technology, Vallabh Vidyanagar, Gujarat, India, and was completed in July, 2012.

\section{Materials and methods}

Chemicals and reagents

Reactive Black-5 (chemical formula: $\mathrm{C}_{26} \mathrm{H}_{21} \mathrm{~N}_{5} \mathrm{Na}_{4} \mathrm{O}_{19} \mathrm{~S}_{6}$ ), which is largely used in dyeing of cotton knits wear in a winch machine at various hosiery dye houses locally, was selected for the experiment. It has a molecular weight of $991.82 \mathrm{~g} / \mathrm{mol}$. The solutions of different concentration of reactive black dye were prepared by dissolving accurately weighed dye in de-ionized water. All other chemicals used in this experiment were of analytical reagent (AR) grade, supplied by Merck, India, and were used without further purification.

\section{Membranes}

Hydrophilized polyamide (HPA) membrane of thickness 125 micron with support cloth was used in the study. The membrane was supplied by Permionics Membrane Pvt. Ltd, Baroda, India. It is a thin-film composite membrane element consisting of a non-woven polyester substrate on which a polyethersulfone layer is coated. The molecular weight cut-off (MWCO) of the membrane was 150, operating $\mathrm{pH}$ range $2-11$, and pure water permeability at ambient temperature was $2.58 \times 10^{-11} \mathrm{~m}^{3} / \mathrm{m}^{2} \mathrm{~s}$ Pa. The membrane was prepared by solution casting and phase inversion gelling. The effective membrane areas were 0.016 and $0.3 \mathrm{~m}^{2}$ for flat sheet and spiral wound module, respectively.

\section{Experimental set-up}

A photograph of the nanofiltration pilot plant used in the study is presented in Fig. 1. Feed solution from the feed tank after pressurizing by high-pressure plunger pump $(344-1,375 \mathrm{kPa})$ was taken to the test cell, made of stainless steel (dimension: $225 \times 150 \times 50 \mathrm{~mm}$ ). The test cell housed the flat sheet HPA membrane. The top half of the cell contained the flow distribution chamber and the bottom half was used as the membrane support system. The upper half of the test cell contained a groove for the arrangement of high-density polyethylene (HDPE) 'O' ring to prevent leakage at high-pressure operation. Retentate stream was collected and recycled to the feed tank routed through a rotameter, while the permeate samples were collected and analyzed for various parameters such as $\mathrm{pH}$, total dissolved solid (TDS), conductivity, chemical oxygen demand (COD), etc. The flow rates of permeate and retentate streams were measured by rotameters, the combined value of which gave the feed flow rate. The feed solution was also passed through the spiral wound module (having $50.8 \mathrm{~mm}$ diameter and $304.8 \mathrm{~mm}$ length) made of stainless steel (SS-316), and the same procedure was repeated. A quick release interconnecting coupling of SS 316 was used for changeover of feed line from flat sheet module to spiral wound and vice versa. In both the cases permeate flux was calculated under various pressure conditions. The pilot plant assembly was equipped with variable frequency drive 

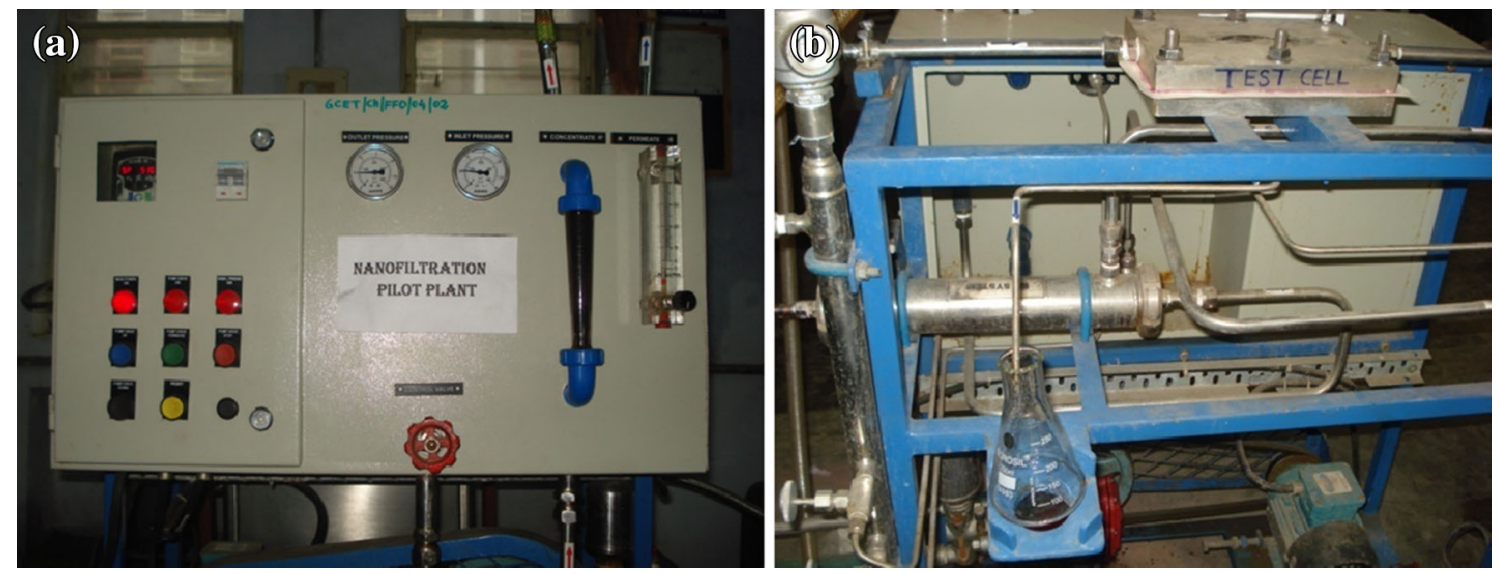

Fig. 1 Photograph of the NF pilot plant $\mathbf{a}$ front view $\mathbf{b}$ rear view

(VFD) for flow control, inlet and outlet pressure gauge, and high-pressure switch.

\section{Operating conditions}

NF experiments were designed to observe the variation of operating conditions on the steady-state permeate flux and retention. While one parameter was varied, the others were held constant to get an exact picture of dependence. All possible combinations were considered. The range of independent variables were pressure $(490,686$ and $980 \mathrm{kPa})$, dye concentration $(12.5,2550$ and $100 \mathrm{mg} / \mathrm{L})$, and salt concentration $(500,750$ and $1,000 \mathrm{mg} / \mathrm{L})$. The dye and salt were analytically weighed to the desired concentrations, depending on the set parameters. For experiments conducted under different conditions (dye concentration, salt content, and feed pressure), samples of permeate and concentrate solutions were collected every $10 \mathrm{~min}$ when the membrane system reached steady state. The steadystate permeate flux was determined by measuring the volume of permeate collected in a given time interval.

\section{Experimental procedure}

First of all, membrane was compacted at the highest operating pressure of $980 \mathrm{kPa}$ for $3 \mathrm{~h}$ with distilled water. Thereafter, to characterize the membrane water, flux was also measured at different pressures to determine the membrane hydraulic resistance. For experimental run, feed tank was filled up with the solution and feed was pumped in the module. The volume of feed solution was $25 \mathrm{~L}$ in the feed tank. Permeate samples were collected at fixed time intervals and concentrations of the same were measured. The permeate stream was recycled back into the feed tank to ensure the constancy of the feed concentration. The experiment was continued till the two consecutive permeate flux data were identical which indicates the attainment of steady state. Duration of each run was $1.5 \mathrm{~h}$ in both flat sheet and spiral wound module. All the experiments were conducted at the prevailing ambient temperature of $32 \pm 2{ }^{\circ} \mathrm{C}$. After each run, feed tank and the set up, including the membrane, were washed thoroughly for $1 \mathrm{~h}$ by recirculating distilled water. After such thorough washing, water run was again taken to measure the change in hydraulic resistance of the membrane.

\section{Permeate and retentate concentration}

The concentration of permeate and retentate streams was analyzed by UV-Vis spectrophotometer (Systronics, model 117). The wave length of maximum absorption $\left(\lambda_{\max }\right)$ of the reactive dye was determined to be $595 \mathrm{~nm}$. A calibration plot of absorbance versus reactive dye concentration at $\lambda_{\max }$ of $595 \mathrm{~nm}$ was constructed. Color intensity was also measured by a HACH DR-2010 model spectrophotometer following USEPA approved HACH method \# 8000 (APHA. American Public Health Association 2005). For color measurements, this device was calibrated at a wavelength of $455 \mathrm{~nm}$ with $\mathrm{Pt}-\mathrm{Co}$ standard solution. Concentrations of salts (single salt solutions only) were determined by conductivity, measured at $25 \pm 0.5{ }^{\circ} \mathrm{C}$ using an auto-ranging conductivity/TDS meter (Hanna Instruments, Taiwan). The concentration of chloride was determined by potentiometric titration using $0.1 \mathrm{M}$ $\mathrm{AgNO}_{3}$.

\section{Measurement of COD, TDS, $p H$ and conductivity}

Chemical oxygen demand (COD), total dissolved solid (TDS), $\mathrm{pH}$ and conductivity of the feed and permeate streams were measured following standard methodologies (APHA. American Public Health Association 2005). Freshly prepared $1 \mathrm{M} \mathrm{NaOH}$ and $\mathrm{HCl}$ solutions were used for $\mathrm{pH}$ adjustment during $\mathrm{pH}$ study. 


\section{AFM and SEM analysis}

Quantitative surface roughness analysis of the HPA nanofiltration membrane before and after use was performed using atomic force microscopy (AFM) imaging and analysis (Park Instrument Auto Probe CT). Membrane samples, being dried under vacuum at $40{ }^{\circ} \mathrm{C}$ for $24 \mathrm{~h}$, were fixed on a specimen holder and $10 \mu \mathrm{m} \times 10 \mu \mathrm{m}$ areas were scanned by tapping mode in air. The surface roughness was reported in terms of the root mean square roughness (Rms). The cross-section and surface morphologies of the membrane were examined by scanning electron microscopy (SEM) using a JEOL/JSM-633F-INCA instrument with an accelerating voltage of $10.0 \mathrm{kV}$.

\section{Determination of flux decline and fouling index}

Permeate flux $\left(J_{p}\right)$ of the membrane was determined using Eq. (1)

$J_{p}=\frac{1}{A} \frac{d V}{d t}$

where $J_{p}$ is the permeate flux $\left(\mathrm{m}^{3} / \mathrm{m}^{2} \mathrm{~s}\right)$, ' $A$ ' is the effective membrane area $\left(\mathrm{m}^{2}\right)$, and $d V / d t$ is the permeate flow rate $\left(\mathrm{m}^{3} / \mathrm{s}\right)$.

Membrane retention coefficient $(R)$ was estimated using Eq. (2)

$R=\left(1-\frac{C_{p}}{C_{b}}\right) \times 100$

where $C_{p}$ is the concentration of the permeate and $C_{b}$ is the bulk concentration of feed solution.

The fouling index was obtained by using the following equation:

$J=J_{p} V_{p}^{-b}$

where $J$ is the initial flux, $V_{p}$ is the cumulative permeate volume, and $b$ is the fouling index.

The decrease in the flux $F_{d}$ was determined using Eq.(4):

$F_{d}=\frac{J_{w}-J_{p}}{J_{w}}$

where $J_{w}$ is the pure water flux.The irreversible fouling $\left(F_{\text {irr }}\right)$ was determined using Eq. (5):

$F_{\text {irr }}=\frac{J_{w}-J_{w 1}}{J_{w}}$

where $J_{\mathrm{w} 1}$ is the pure water flux measured after cleaning. The flux recovery $F_{r}$ was determined using Eq. (6):

$F_{r}=\frac{J_{w 1}}{J_{w}}$
Evaluation of specific energy consumption (SEC)

Specific energy consumption (SEC) is defined as the energy consumed for every $\mathrm{m}^{3}$ of feed water processed; thus the SEC $\left(\mathrm{kW} \mathrm{h} / \mathrm{m}^{3}\right)$ can be calculated at every operating condition using Eq. (7):

$\mathrm{SEC}=\frac{\sqrt{3} V I \cos \phi}{1,000 Q}$

where $V$ is the voltage, $I$ is the average current for a particular set of conditions, $\cos \phi$ is the power factor (cosine of the phase angle between voltage and current), and $Q$ is the feed flow rate $\left(\mathrm{m}^{3} / \mathrm{h}\right)$.

\section{Results and discussion}

The permeate flux and observed retention at steady state are the most important indices for the performance of a nanofiltration process. Effects of operating conditions such as feed dye concentration, feed salt concentration, pressure difference, and initial feed $\mathrm{pH}$ on steady-state permeate flux and observed retention of salt and dye are discussed in the following sections for flat sheet and spiral wound modules.

\section{Effect of different feed dye concentration}

The selection of feed dye concentration plays an important role while studying the flux and retention behavior of an asymmetric NF membrane. The flux through the membrane becomes too low for a comparative study at higher feed concentrations. Considering this, the upper level of feed concentration was chosen as $100 \mathrm{mg} / \mathrm{L}$ which was close to the concentration of dye discharged from smaller scale textile units. Experiments were conducted by fixing the $\mathrm{NaCl}$ concentration at $500 \mathrm{mg} / \mathrm{L}$, while varying the dye concentration from 12.5 to $100 \mathrm{mg} / \mathrm{L}$ for about $90-100 \mathrm{~min}$ until steady-state flux was observed. The trans-membrane pressure (TMP) was maintained at $686 \mathrm{kPa}$. Effect of feed dye concentration on the permeate flux and observed salt retention in both modules are described in Fig. 2. It was evident that permeate flux and observed retention decreased with increase in feed dye concentration. As concentration of dye increases, the activity and thus the osmotic pressure of the solution increases as well. As a result, membrane surface concentration increases, leading to an increase in the osmotic pressure of the solution close to the membrane. This reduces the net driving force for the solvent flux. This effect is more prominent at higher feed concentrations.

A perusal of Fig. 2 also indicates that for all the dye concentrations, the steady-state permeate fluxes obtained in 
Fig. 2 Variation of steady-state permeate flux and observed rejection at different feed dye concentration in two different membrane modules with fixed salt concentration of $500 \mathrm{mg} / \mathrm{L}$ (TMP $686 \mathrm{kPa})(S W$ spiral wound, $F S$ flat sheet)

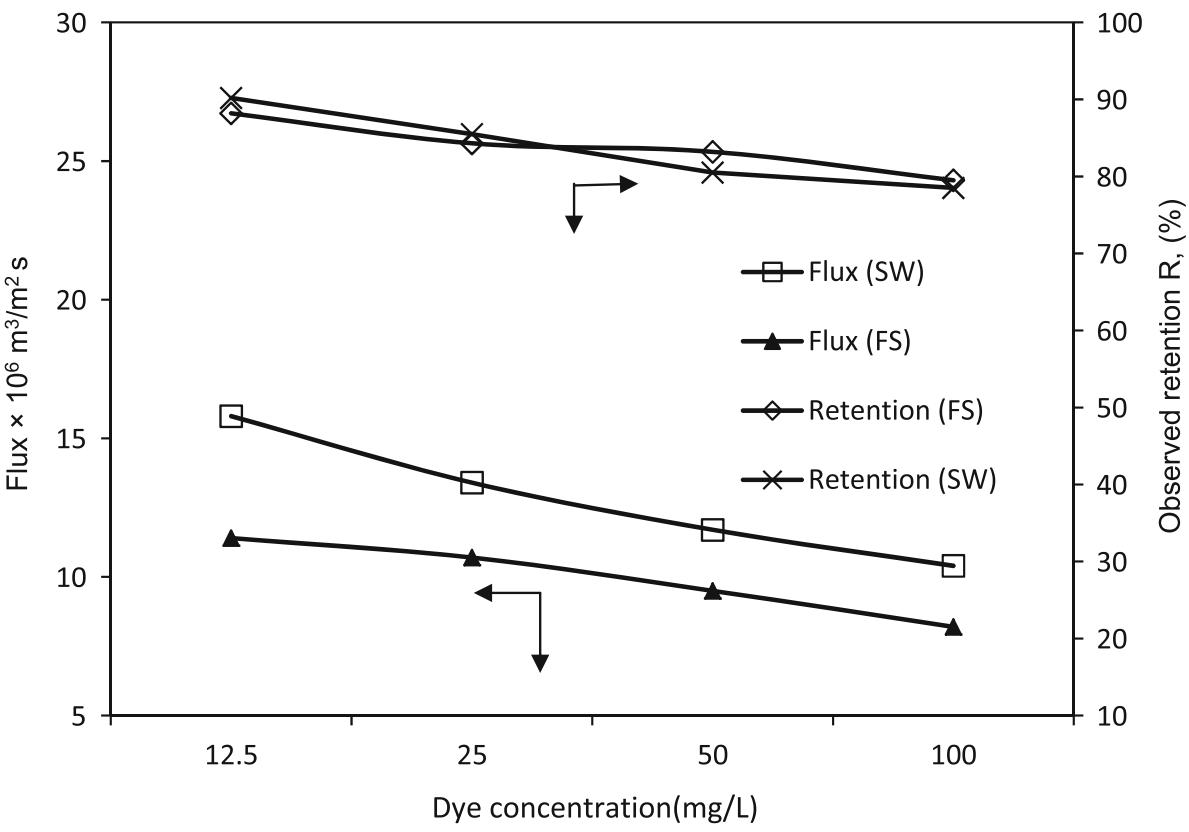

spiral wound module were marginally higher than those obtained in flat sheet. The volume of permeate collected in spiral wound module during each run was greater than that collected in flat sheet. The area of spiral wound module was higher than that of flat sheet counterpart. But the magnitude of flux was not significantly high in flat sheet. The chances of entrance effect and channeling of feed solution in the flat sheet membrane might have reduced the filtration area actually available, regardless of the fact that it was having thin-wire spacers to prevent the same. This was clear from the visual observation of the used flat sheet membrane stained with reactive dye (not shown). However, the decline in permeate flux was more in the case of spiral wound module compared with flat sheet. This was also observed in the flux decline studies which are discussed little later. Braghetta et al. (1997) indicated that the electric double layer of membrane was reduced in the presence of higher solute concentrations, and the structure of the membrane was found to be more compacted. Consequently, the permeate flux through the membrane was reduced as the solute concentration in the feed increased. Therefore, a suitable operating feed dye concentration should be chosen to treat reactive dye salt mixture to have a reasonable permeate flux and retention.

Effects of feed dye concentration on the percent dye removal for both the modules were also studied. The dye removal rates in both the modules were at the level of above $99 \%$ and higher color removals were obtained for all the feed dye concentrations tested in the experiments. The dye removal rate initially decreased when feed dye concentration increased up to $50 \mathrm{mg} / \mathrm{L}$ from $12.5 \mathrm{mg} / \mathrm{L}$ and then ascended slightly with further increase in dye concentration from 50 to $100 \mathrm{mg} / \mathrm{L}$. The initial trend of percent color removal indicates that the extent of color removal increased with decreasing initial feed concentration; however, the trend was not uniform. Theoretically, at higher feed dye concentration, the electrostatic repulsive interaction between the HPA membrane and the charged reactive dye should decrease leading to a lower rate of dye removal (Yu et al. 2010). But in the present study the maximum dye removal rate at high feed dye concentration is probably attributed to the presence of salt. The concentration polarization layer formed by the salt might have acted as an additional barrier to the passage of the color together with the barrier formed by the dye concentration polarization layer (Al-Aseeri et al. 2007).

\section{Effect of different feed salt concentration}

Variation of steady-state permeate flux and observed salt retention at different feed salt concentration in two different membrane modules are presented in Fig. 3. The plot indicates that with a fixed dye concentration, the increase in salt content leads to a slight decrease in the permeate flux. The phenomenon of flux decline was primarily because of significant concentration polarization effect at high salt concentration. However, a close inspection of Fig. 3 reveals that the decline in flux from 750 to $1,000 \mathrm{mg} / \mathrm{L}$ salt concentration is not substantial for spiral wound module. At high $\mathrm{NaCl}$ concentration due to the high ionic strength and reduction in dye hydrophobicity less concentration polarization effect of dye was observed. In addition, the tendency of dye molecules to be adsorbed on the membrane surface decreased at high ionic strength (Koyuncu and Topacik 2002). Therefore, flux values were less affected by the changes in $\mathrm{NaCl}$ concentrations. 
Fig. 3 Variation of steady-state permeate flux and salt rejection at different feed salt concentration in two different membrane modules with fixed dye concentration of $25 \mathrm{mg} / \mathrm{L}$ ( $S W$ spiral wound, $F S$ flat sheet)

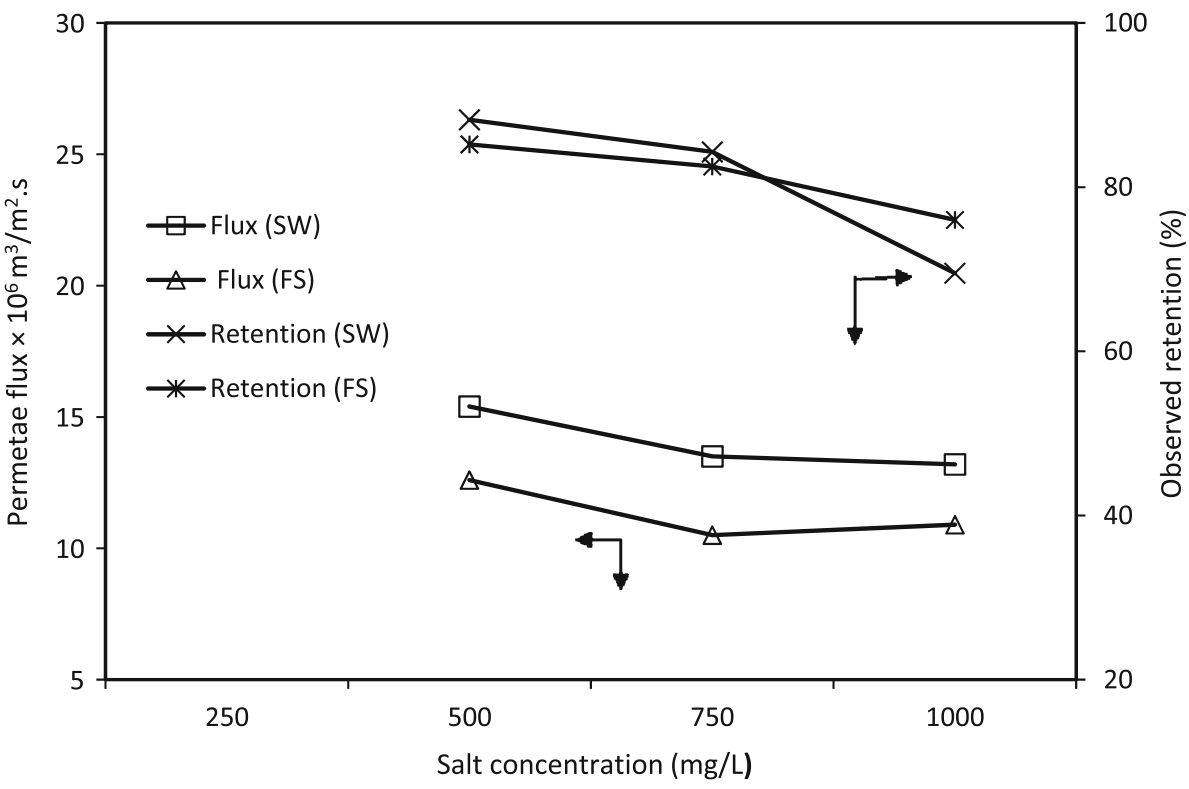

However, further studies need to be carried out to ascertain the performance of various modules towards flux decline details.

The increase in $\mathrm{NaCl}$ concentration from 500 to $1,000 \mathrm{mg} / \mathrm{L}$ resulted in the reduction of observed retention from 85.2 to $76 \%$ for flat sheet module, whereas for spiral wound module observed retention decreased from 88.2 to $69.5 \%$ (Fig. 3). The Donnan effect most likely plays an important role in retaining salt in the membrane and the Donnan exclusion becomes less effective with increasing salt content. The higher concentration of $\mathrm{Cl}^{-}$ions in the feed solution contributes to an increase in the ionic or Donnan equilibrium of the $\mathrm{Cl}^{-}$ions in the membrane. This results in the higher ionic fluxes through the membranes with consequent lower salt retentions (Jiraratananon et al. 2000). The extent of dye removal from dye/salt mixtures was also studied under three different salt concentrations but with a fixed dye concentration of $25 \mathrm{mg} / \mathrm{L}$ employing both the modules. The dye retentions for all the salt concentrations were more than $99 \%$. Although not significant, the dye retention at $1,000 \mathrm{mg} / \mathrm{L}$ salt concentration (99.69\% for flat sheet; $99.67 \%$ for spiral wound) was marginally less than the dye retention at $500 \mathrm{mg} / \mathrm{L}$ salt concentration $(99.75 \%$ for flat sheet; $99.83 \%$ for spiral wound). Moreover, there was no noticeable difference in dye removal behavior of flat sheet and spiral wound module.

\section{Flux decline during NF}

Decline in permeate flux over the period of operation is one of the major drawbacks in all the pressure driven membrane processes. It is widely recognized that membrane fouling is mainly responsible for flux decline. A typical comparative plot of decline in flux for nine different dye-salt combinations with respect to time of operation is presented in Fig. 4 for spiral wound module. A perusal of the plot indicates that as the total feed concentration (both reactive dye and $\mathrm{NaCl}$ ) increases, there is a gradual decrease in permeate flux. For the combination of $50 \mathrm{mg} / \mathrm{L}$ dye and $1,000 \mathrm{mg} / \mathrm{L} \mathrm{NaCl}$ concentration, the permeate flux reduced to $10.14 \times$ $10^{-6} \mathrm{~m}^{3} / \mathrm{m}^{2} \mathrm{~s}$ from an initial value of $10.75 \times 10^{-6} \mathrm{~m}^{3} /$ $\mathrm{m}^{2} \mathrm{~s}$ after $90 \mathrm{~min}$ of operation. The initial decline in permeate flux was primarily due to the build-up of osmotic pressure of the solution, whereas the gradual decline could be considered as a combined effect of build-up of deposited layer on the membrane surface and deposition of solute particles in the membrane pores (Pastagia et al. 2003). The effects reduced the permeation of solvent. Finally, the permeate flux attained a steady-state value which was probably limited by the external hydrodynamic conditions like cross-flow velocity, stirring, and turbulence. However, hydrodynamics were not studied in the present work. Experimentally, it was observed that flux decline started just after 15 min of operation and eventually became steady after a long time of operation. This may be termed as longterm flux decline. Long-term decline may be caused due to the slow formation of a deposited layer above the membrane surface, which grows over time (Satyanarayana et al. 2000). Flux decline $F_{d}$, the irreversible fouling $F_{\text {irr }}$, and the flux recovery $F_{r}$, for HPA membrane were determined using Eqs. (2) to (6). The flux decline of the HPA membrane was mostly reversible, and the water flux recovery was close to $100 \%$ without the use of any cleaning agents (data not shown). The fouling index and irreversible fouling $F_{\text {irr }}(\%)$ were 0.022 and 4.41, respectively. The results suggest that the HPA membrane was not much fouled by the reactive red dyes and thus exhibited antifouling properties. Zularisam 


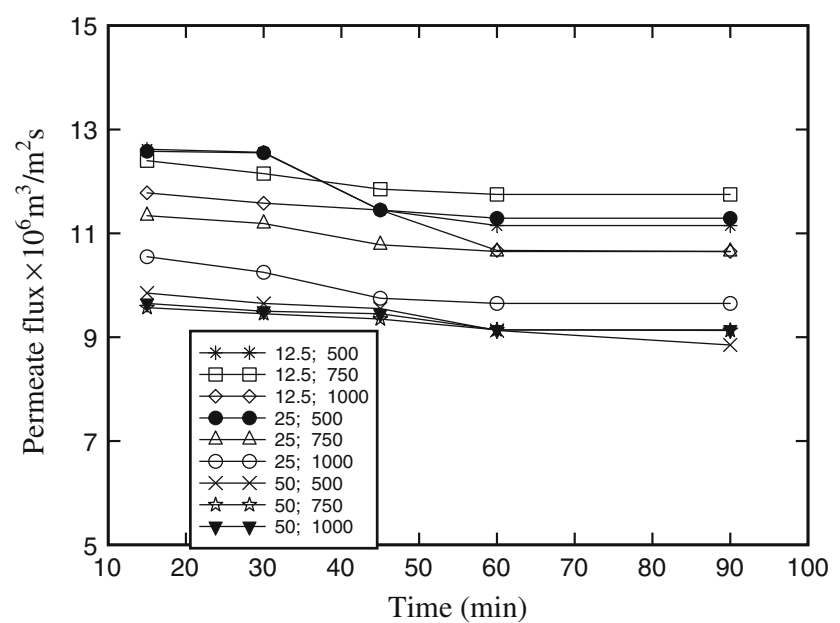

Fig. 4 Variation of permeate flux with time at various combinations of dye-salt mixture at a fixed TMP in flat sheet $(686 \mathrm{kPa})$ (dye concentrations: $12.5,25$, and $50 \mathrm{mg} / \mathrm{L}$; salt concentrations 500,750 and $1,000 \mathrm{mg} / \mathrm{L}$ )

et al. (2007) found that the hydrophilic fraction exhibited a better flux recovery. The same observation was made in this investigation.

\section{Effect of different feed pressure}

Figure 5 presents the variation of permeate flux with transmembrane pressure for different salt concentration in spiral wound and flat sheet membranes. Dye concentration was fixed at $12.5 \mathrm{mg} / \mathrm{L}$. This figure reveals that increasing transmembrane pressure from $490 \mathrm{kPa}$ to 686 and $980 \mathrm{kPa}$ led to an increase in permeate flux both in flat sheet and spiral wound membrane and that the flux profiles were higher in values for higher operating pressures. At higher operating pressure the driving force across the membrane for solvent transport increases, leading to an enhancement of permeate flux (Chakraborty et al. 2003, Satyanarayana et al. 2000). In spiral wound membrane with $1,000 \mathrm{mg} / \mathrm{L}$ $\mathrm{NaCl}$ concentration, permeate flux at $490 \mathrm{kPa}$ was estimated to be $9.78 \times 10^{-6} \mathrm{~m}^{3} / \mathrm{m}^{2} \mathrm{~s}$ and this was enhanced to $14.75 \times 10^{-6} \mathrm{~m}^{3} / \mathrm{m}^{2} \mathrm{~s}$ at $980 \mathrm{kPa}$. With increase in pressure drop from 490 to $980 \mathrm{kPa}$ the flux enhancement of the permeate stream having 500 and $750 \mathrm{mg} / \mathrm{L}$ feed salt concentrations was about 35.43 and $33.31 \%$, respectively. The similar trend of flux enhancement was also observed in flat sheet membrane although a maximum of $31.1 \%$ increase was recorded with $1,000 \mathrm{mg} / \mathrm{L}$ feed salt concentration. This is an indication of the fact that the membrane is quite stable and does not get compacted or stretched at higher pressure. The initial low rate of flux increase is due to the variation in transmembrane pressure and the inlet pressure at lower and higher pressure operation. In the former case the pressure drop across the membrane and in the system pipe line becomes quite significant in relation to

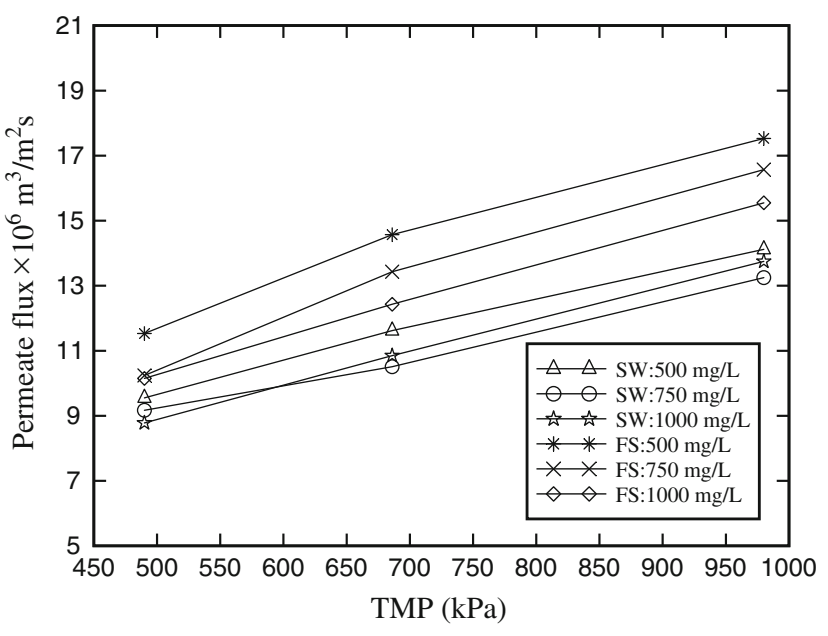

Fig. 5 Variation of permeate flux in spiral wound and flat sheet membranes with different pressure for different salt concentration ( $S W$ spiral wound, $F S$ flat sheet). Fixed dye concentration: $12.5 \mathrm{mg} / \mathrm{L}$

the pressure of operation, compared with the case of higher pressure (Rai et al. 2000).

\section{Effect of Feed pH}

$\mathrm{pH}$ of the feed solution is an important operational parameter to be controlled since it affects the NF separation performance to a great extent. The variation of permeate flux and observed salt retention with time of operation at four different $\mathrm{pH}$ values in flat sheet module is shown in Fig. 6. Reactive Black-5 and $\mathrm{NaCl}$ were mixed at the concentrations of 25 and $500 \mathrm{mg} / \mathrm{L}$, respectively. TMP was maintained at $490 \mathrm{kPa}$. Permeate flux decreased with lapse of time as expected but the lowest flux values were obtained at high $\mathrm{pH}$. However, there were no important differences on the flux values of the runs conducted at $\mathrm{pH} 5$ (acidic) and $\mathrm{pH}$ 7 (neutral). The trend of flux variation as a function of $\mathrm{pH}$ in spiral wound module (data not shown) was not much different from that in the flat sheet. The formation of a strong and stable dye-salt complex at higher $\mathrm{pH}$ results in an increase in dye hydrophobicity which causes adsorption of dye molecules on the membrane surface (Yeung and Shang 1999). Attraction of molecules to the membrane surface due to charge interactions enhances flux decline at alkaline conditions. The use of high salt concentrations in exhaust dyeing decreases the solubility of the dye and increases the ionic strength as well as degree of aggregation of dye molecules via common ion effect under alkaline conditions (Hamlin et al. 1999). Additionally at low pH, the functional groups from the molecules are not dissociated and the surface charge is weak. As a consequence, electrostatic repulsion forces between the organic matter and the membrane surface decrease and fouling increases (García-Molina et al. 2006). In a similar study of textile waste water 
Fig. 6 Variation of permeate flux and observed salt rejection with time under different $\mathrm{pH}$ conditions (dye concentration: $25 \mathrm{mg} / \mathrm{L} ; \mathrm{NaCl}$ concentration: $500 \mathrm{mg} / \mathrm{L}$, TMP: $490 \mathrm{kPa}$.) in flat sheet module

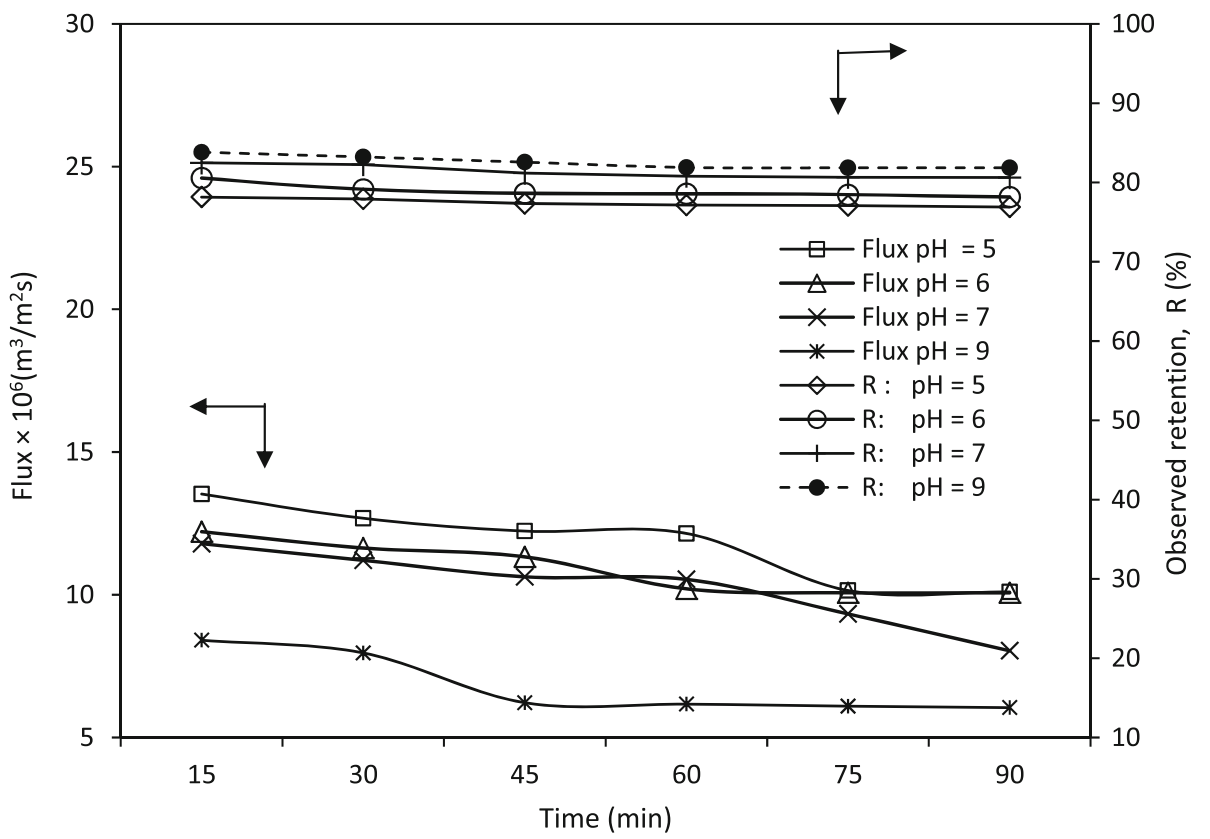

reclamation by nanofiltration, the variable flux behavior with respect to feed water $\mathrm{pH}$ was reported. For $\mathrm{pH} 8$ and 11 the influence of $\mathrm{pH}$ was negligible. However, at $\mathrm{pH} 5$ the permeate flux was the best for each TMP. The maximum permeate flux of $82 \mathrm{~L} / \mathrm{m}^{2} \mathrm{~h}$ was obtained at 10 bar and $\mathrm{pH} 5$ (Alcaina-Miranda et al. 2009).

Figure 6 also revealed that initially the salt retention $\left(R_{o}\right)$ decreased gradually but thereafter the decrease was not appreciable. Ideally, at the beginning of the run permeate concentration $\left(C_{p}\right)$ decreases rapidly, resulting in sharp increase in $R_{o}$ and thereafter because of solute build up over the membrane surface, as a result of concentration polarization, permeate concentration tends to increase gradually. Increased permeate concentration led to the decline in observed retention. Towards the end of operation decrease in salt retention was negligible probably due to almost steady permeate concentration. However, a careful observation of Fig. 6 indicates a noticeably different magnitude of salt retention under different $\mathrm{pH}$ conditions. Low salt retention was observed at acidic $\mathrm{pH}$ conditions $(\mathrm{pH}=5)$, compared with alkaline $\mathrm{pH}(\mathrm{pH}=9)$. The values of maximum observed retention were 78.16, 80.56, 82.47 , and $83.82 \%$ at pH 5, 6, 7, and 9, respectively. Similar results were obtained in spiral wound module; however, the $R_{o}$ values were found to vary within a narrow range (data not shown). Since the removal mechanism of NF is not only sieving, charge interactions also play an important role in the retention performance.

\section{Permeate quality}

In the present study, the permeate quality was evaluated by measuring COD, color, conductivity, and TDS of the permeate streams under different experimental conditions. These are presented in Table 1 for flat sheet and spiral wound modules. The values of these parameters are mostly within permissible limits of reuse criteria irrespective of the module configurations (BTTG 1999; Goodman and Porter 1980). As observed from Table 1, the dye removal efficiency of both the modules was remarkably high being in the range of 99.24-99.87\%. The visual observation of the permeate samples indicated that they were virtually colorless. A maximum of $98.87 \%$ color removal was achieved using flat sheet membrane for a feed of $12.5 \mathrm{mg} / \mathrm{L}$ concentration, whereas for 25 and $50 \mathrm{mg} / \mathrm{L}$ feed concentrations maximum color removal were recorded as 99.75 and $99.82 \%$, respectively. On the other hand, maximum color removal was $99.83 \%$ in spiral wound module. It can be conclusively said from this result that the HPA membrane with MWCO 150 is good enough to remove the dyes with higher molecular weights. While the effect of increasing pressure was noticeable in getting a higher permeate flux and a better recovery with or without $\mathrm{NaCl}$, this was not the case when considering the color removal where changing pressure did not seem to affect the percentage dye removal. Also the effect of the presence of salts to augment the extent of dye retention, as discussed earlier, cannot be ruled out.

In addition to high color retention, the HPA membrane also provided quite high COD rejection. The COD retention was in the range of 95 to $97 \%$ for all the experimental conditions. The average COD values of the permeate streams obtained from the feed having $12.5,25$ and $50 \mathrm{mg} /$ $\mathrm{L}$ dye concentrations were found to be $84.5,90$, and $85 \mathrm{mg} /$ L, respectively. Uzal et al. (2010) reported $94 \%$ COD 
Table 1 Qualitative properties of the permeate stream using flat sheet and spiral wound module for various dye-salt combination

\begin{tabular}{|c|c|c|c|c|c|c|c|c|c|}
\hline \multirow[t]{2}{*}{ Feed composition dye; salt (mg/L) } & \multirow{2}{*}{$\begin{array}{l}\Delta \mathrm{P} \\
(\mathrm{kPa})\end{array}$} & \multicolumn{4}{|c|}{ Flat sheet module } & \multicolumn{4}{|c|}{ Spiral wound module } \\
\hline & & $\begin{array}{l}\text { Dye removal } \\
(\%)\end{array}$ & $\begin{array}{l}\text { COD } \\
(\mathrm{mg} / \mathrm{L})\end{array}$ & $\begin{array}{l}\text { Conductivity } \\
(\mu \mathrm{S} / \mathrm{cm})\end{array}$ & $\begin{array}{l}\text { TDS } \\
(\mathrm{mg} / \mathrm{L})\end{array}$ & $\begin{array}{l}\text { Dye removal } \\
(\%)\end{array}$ & $\begin{array}{l}\text { COD } \\
(\mathrm{mg} / \mathrm{L})\end{array}$ & $\begin{array}{l}\text { Conductivity } \\
(\mu \mathrm{S} / \mathrm{cm})\end{array}$ & $\begin{array}{l}\text { TDS } \\
(\mathrm{mg} / \mathrm{L})\end{array}$ \\
\hline $12.5 ; 500 \mathrm{TDS}=1,036 \mathrm{mg} / \mathrm{L}$ & 490 & 99.58 & 116 & 192.30 & 125 & 99.83 & 100 & 184.61 & 120 \\
\hline Conductivity $=1,593.8 \mu \mathrm{S} / \mathrm{cm}$ & 686 & 99.64 & 107 & 230.77 & 150 & 99.84 & 103 & 153.84 & 100 \\
\hline $\mathrm{COD}=2,179 \mathrm{mg} / \mathrm{L}$ & 980 & 99.24 & 95 & 261.54 & 170 & 99.87 & 69 & 384.61 & 250 \\
\hline $12.5 ; 750 \mathrm{TDS}=1,360 \mathrm{mg} / \mathrm{L}$ & 490 & 99.75 & 103 & 230.77 & 150 & 99.76 & 120 & 292.30 & 190 \\
\hline Conductivity $=2,092.3 \mu \mathrm{S} / \mathrm{cm}$ & 686 & 99.45 & 112 & 289.23 & 188 & 99.78 & 103 & 230.76 & 150 \\
\hline $\mathrm{COD}=2,170 \mathrm{mg} / \mathrm{L}$ & 980 & 99.56 & 39 & 369.23 & 240 & 99.75 & 120 & 307.69 & 200 \\
\hline $12.5 ; 1,000 \mathrm{TDS}=1,345 \mathrm{mg} / \mathrm{L}$ & 490 & 99.69 & 103 & 235.38 & 153 & 99.81 & 132 & 492.30 & 320 \\
\hline Conductivity $=2,461.5 \mu \mathrm{S} / \mathrm{cm}$ & 686 & 99.87 & 108 & 400 & 260 & 99.83 & 100 & 476.92 & 310 \\
\hline $\mathrm{COD}=2,179 \mathrm{mg} / \mathrm{L}$ & 980 & 99.73 & 80 & 476.92 & 310 & 99.63 & 62 & 369.23 & 240 \\
\hline $25 ; 500 \mathrm{TDS}=1,080 \mathrm{mg} / \mathrm{L}$ & 490 & 99.75 & 98 & 192.3 & 125 & 99.83 & 104 & 184.61 & 120 \\
\hline Conductivity $=1,661.5 \mu \mathrm{S} / \mathrm{cm}$ & 686 & 99.34 & 100 & 215.38 & 140 & 99.72 & 89 & 169.23 & 110 \\
\hline $\mathrm{COD}=1,320 \mathrm{mg} / \mathrm{L}$ & 980 & 99.70 & 110 & 200 & 130 & 99.77 & 74 & 184.61 & 120 \\
\hline $25 ; 750 \mathrm{TDS}=1,270 \mathrm{mg} / \mathrm{L}$ & 490 & 99.53 & 100 & 307.69 & 200 & 99.75 & 110 & 184.61 & 120 \\
\hline Conductivity $=1,953.8 \mu \mathrm{S} / \mathrm{cm}$ & 686 & 99.23 & 62 & 276.92 & 180 & 99.78 & 86 & 169.23 & 110 \\
\hline $\mathrm{COD}=1,180 \mathrm{mg} / \mathrm{L}$ & 980 & 99.65 & 83 & 338.46 & 220 & 99.49 & 79 & 307.69 & 200 \\
\hline $25 ; 1,000 \mathrm{TDS}=1,230 \mathrm{mg} / \mathrm{L}$ & 490 & 99.69 & 69 & 307.69 & 200 & 99.67 & 89 & 430.76 & 280 \\
\hline Conductivity $=2,815.3 \mu \mathrm{S} / \mathrm{cm}$ & 686 & 99.39 & 104 & 246.15 & 160 & 99.45 & 96 & 246.15 & 160 \\
\hline $\mathrm{COD}=1,080 \mathrm{mg} / \mathrm{L}$ & 980 & 99.57 & 89 & 307.69 & 200 & 99.39 & 87 & 369.23 & 240 \\
\hline $50 ; 500 \mathrm{TDS}=1,210 \mathrm{mg} / \mathrm{L}$ & 490 & 99.58 & 86 & 323.07 & 210 & 99.5 & 88 & 215.38 & 140 \\
\hline Conductivity $=1,861.5 \mu \mathrm{S} / \mathrm{cm}$ & 686 & 99.23 & 79 & 230.76 & 150 & 99.47 & 79 & 169.23 & 110 \\
\hline $\mathrm{COD}=1,136 \mathrm{mg} / \mathrm{L}$ & 980 & 99.47 & 92 & 200 & 130 & 99.64 & 116 & 200 & 130 \\
\hline $50 ; 750 \mathrm{TDS}=1,270 \mathrm{mg} / \mathrm{L}$ & 490 & 99.75 & 96 & 353.84 & 230 & 99.69 & 92 & 184.61 & 120 \\
\hline Conductivity $=1,953.8 \mu \mathrm{S} / \mathrm{cm}$ & 686 & 99.82 & 87 & 276.92 & 180 & 99.55 & 103 & 207.69 & 135 \\
\hline $\mathrm{COD}=1,630 \mathrm{mg} / \mathrm{L}$ & 980 & 99.67 & 86 & 369.23 & 240 & 99.73 & 105 & 276.92 & 180 \\
\hline $50 ; 1,000 \mathrm{TDS}=1,285 \mathrm{mg} / \mathrm{L}$ & 490 & 99.47 & 74 & 230.76 & 150 & 99.45 & 86 & 307.69 & 200 \\
\hline Conductivity $=1,569.2 \mu \mathrm{S} / \mathrm{cm}$ & 686 & 99.28 & 88 & 400 & 260 & 99.46 & 106 & 238.46 & 155 \\
\hline $\mathrm{COD}=1,220 \mathrm{mg} / \mathrm{L}$ & 980 & 99.32 & 79 & 307.69 & 200 & 99.53 & 113 & 307.69 & 200 \\
\hline
\end{tabular}

retention in the nanofiltration of rinsing wastewater from indigo dyeing. In another study Chakraborty et al. (2003) obtained COD retention up to $94 \%$ using NF for the treatment of dyeing wastewater. COD removal efficiencies in membrane processes depend on the wastewater characteristics and membrane type. This indicates that the particular HPA membrane is highly suitable for the organic solute separation under experimental conditions prevailing in the system. NF membranes have the potential to remove dissolved solid causing TDS. However, complete TDS removal was not achieved with the HPA membrane. The TDS of permeate streams showed a much lesser extent of separation being in the range of $85-88 \%$ for all concentrations of feed stream. This is somewhat expected as the total dissolved solids are composed of both organic and inorganic solids. The nanofiltration membrane with larger pore structures allowed smaller inorganics such as $\mathrm{NaCl}$ while retaining most of the larger organic molecules (reactive dye), thereby contributing to the lesser reduction of TDS. The results can be further interpreted following the observations by Allegre et al. (2004) who explained this behavior by the electrostatic interactions between effluent and membrane. In presence of salts like $\mathrm{NaCl}$, the electrostatic repulsions at the membrane wall become weak and the salts can pass easily through the membrane.

AFM and SEM analysis of the membrane

The surface morphology of the HPA-NF membranes was investigated in this study by atomic force microscopy (AFM) imaging. The AFM images of the virgin (unused) membrane and the membrane after use are shown in Fig. 7. A much larger scale $\mathrm{Z}$-axis was used for the image of the composite HPA-NF membrane. The AFM data clearly show that the thin-film composite HPA-NF membrane exhibits certain amount of surface roughness of ridge-andvalley structure. The root mean square roughness of the HPA membrane was determined to be $0.109 \mu \mathrm{m}$. The 

HPA membrane a virgin $\mathbf{b}$ after use
Fig. 7 AFM images of the
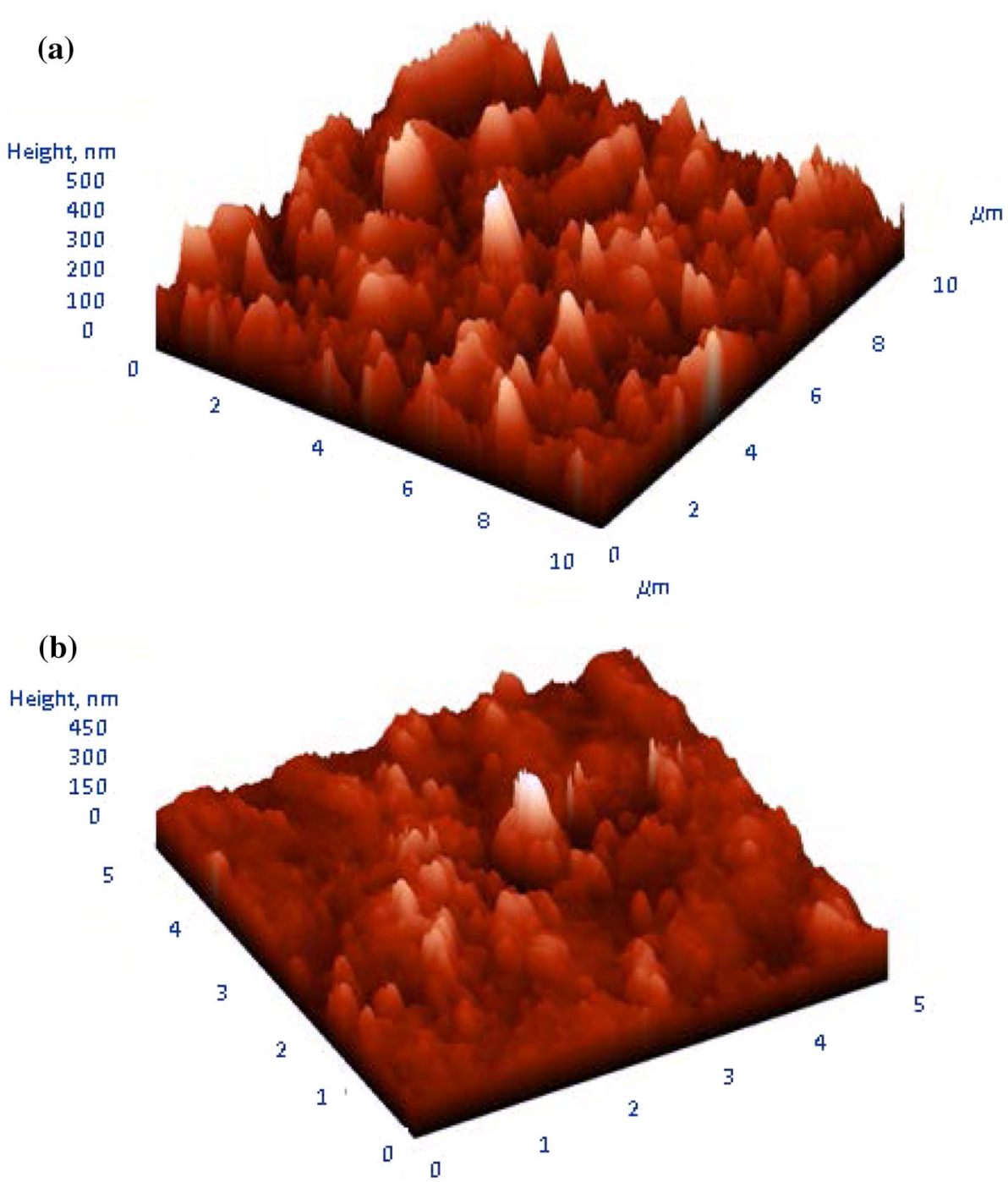

distinct roughness of the composite membrane is an inherent property of interfacially polymerized aromatic polyamide composite membranes (Yu et al. 2010). Further, a close observation of the AFM image of the used HPA-NF membrane reveals that the ridges are not distinctly visible compared with the virgin membrane. Probably, the ridges are shrouded with retained dye molecules and deposited salt particles. The SEM micrographs of the top surface and cross section morphologies of the virgin and used HPA-NF membrane are presented in Fig. 8. Scattered pores are visible on the surface the virgin membrane, but in the used membrane pores are mostly covered with dye and salt particles. Only few pores are visible in the used membrane surface, but their sizes are reduced by the deposition of the layers of dye and salt particles.

Specific energy consumption

Reclamation of dye-salt mixture by nanofiltration may become attractive from both economic and operational points of view only when the energy consumption due to pressure generation is minimized. In order to assess the efficiency of any recovery system, the total energy consumption of the pilot plant has to be found for a long period of time and the specific energy consumption could be calculated in $\mathrm{kWh}$ per $\mathrm{m}^{3}$ of water processed. Keeping this in mind, the specific energy consumption of the high-pressure plunger pump at specific operating conditions was calculated at different feed pressures. If the specific energy consumption, SEC is defined as the energy consumed for every $\mathrm{m}^{3}$ of produced water; the SEC can be calculated at every operating condition according to Eq. (7). Some of these data are presented in Table 2. The average SEC in this work, at 490,686, and $980 \mathrm{kPa}$ feed pressure was found to

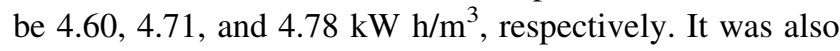
obvious that specific energy consumption increased with increasing feed pressure. Avlonitis et al. (2008) reported the SEC of $3.75 \mathrm{~kW} \mathrm{~h} / \mathrm{m}^{3}$ at $800 \mathrm{kPa}$ feed pressure. In another study of economical feasibility of vegetable tanning liquor recovery by a combined MF-UF method, the energy 

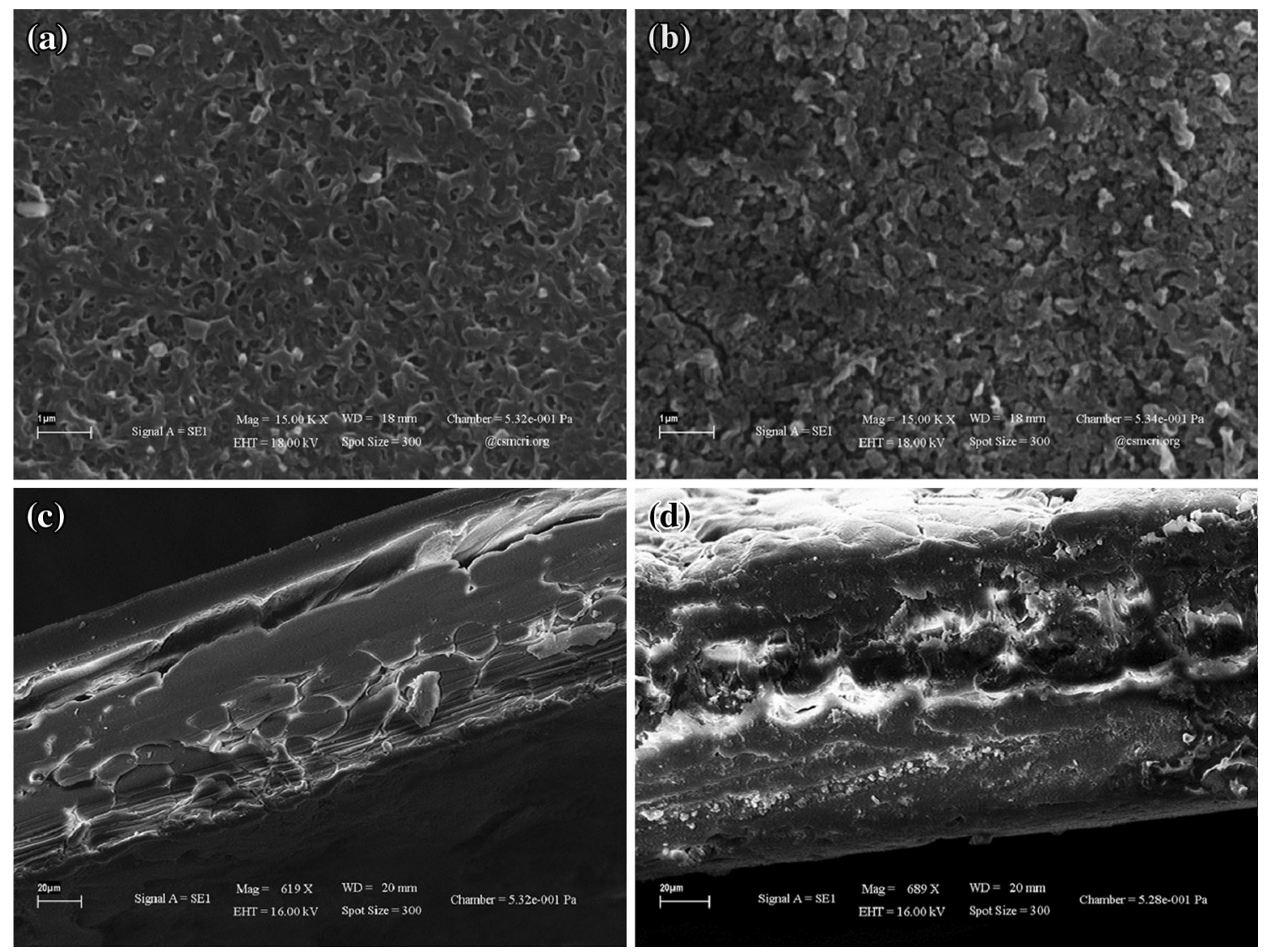

Fig. 8 SEM images of the top surface and cross section of the HPA membrane a virgin (top surface) b virgin (cross section) $\mathbf{c}$ used (top surface) d (cross section)

Table 2 Pressure pumps operating characteristics and specific energy consumption

\begin{tabular}{|c|c|c|c|c|c|c|c|}
\hline \multirow[t]{2}{*}{$P_{\text {feed }}(\mathrm{kPa})$} & \multicolumn{3}{|c|}{ Current (A) } & \multirow[t]{2}{*}{ rpm motor/pump } & \multirow[t]{2}{*}{ Q Feed flow rate $\left(\mathrm{m}^{3} / \mathrm{h}\right)$} & \multirow[t]{2}{*}{ Power (W) } & \multirow{2}{*}{$\begin{array}{l}\text { Specific energy } \\
\text { consumption }\left(\mathrm{kWh} / \mathrm{m}^{3}\right)\end{array}$} \\
\hline & $\mathrm{R}$ & $\mathrm{Y}$ & $\mathrm{B}$ & & & & \\
\hline 490 & 2.62 & 2.53 & 2.59 & $982 / 422$ & 0.36 & $1,658.28$ & 4.60 \\
\hline 686 & 2.68 & 2.56 & 2.62 & $986 / 420$ & 0.36 & $1,697.15$ & 4.71 \\
\hline 980 & 2.74 & 2.60 & 2.65 & $986 / 423$ & 0.36 & $1,723.11$ & 4.78 \\
\hline
\end{tabular}

$R$ (red), $Y$ (yellow), and $B$ (blue) are three phase sequences denoting the order in which their e.m.f achieves maximum value in three-phase equipment. They are $120^{\circ}$ apart from each other and are in positive sequence

consumption was found to be $6 \mathrm{kWh} / \mathrm{m}^{3}$ (Scholz and Lucas 2003). It is worthwhile to note that, in actual plant operation, the consumption of the total energy which is spent for the nanofiltration plant also includes energy consumption for dosing pumps, cleaning pumps, etc. However, in real industrial nanofiltration plants the specific energy consumption should be less than $2 \mathrm{~kW} \mathrm{~h} / \mathrm{m}^{3}$. If small energy consumption is achieved then the ability to reuse the produced water makes the nanofiltration method very attractive to industrial applications. Introduction of more efficient, flexible, and simple energy recovery system like turbo charger may be helpful in achieving better energy saving by lowering the operating pressure of the high-pressure (HP) pump (Maheswari et al. 1995). But detailed energetic and exergetic analysis need to carried out to evaluate the energy efficiency of the process.

\section{Conclusion}

Nanofiltration of an aqueous solution of Reactive Black-5 and $\mathrm{NaCl}$ was studied extensively in two different modules for a range of operating conditions. The results indicate that dye and salt concentrations, initial feed $\mathrm{pH}$, and transmembrane pressure have a role on the permeate flux, salt retention, and permeate quality. Both permeate flux and 
observed salt retention decreased with increase in dye and $\mathrm{NaCl}$ concentration in feed. The steady-state permeate flux obtained in spiral wound module was marginally higher than that obtained in flat sheet. Increasing trans-membrane pressure led to an increase in permeate flux, the magnitude of which was higher for higher operating pressures. The lowest flux values were obtained at high $\mathrm{pH}$. However, there were no important differences on the flux values at neutral and acidic $\mathrm{pH}$ conditions. Low salt retention was observed at acidic $\mathrm{pH}$ conditions $(\mathrm{pH}=5)$, compared with alkaline $\mathrm{pH}(\mathrm{pH}=9)$. High flux values and low salt retention are needed by means of recovery of salt and water. In addition, optimization for the operating pressure, which increases the permeate flux and salt retention, should be done. Substantial removal of color was achieved with a marked reduction in COD and TDS. The dye removal efficiency of both the modules was remarkably high being in the range of $99.24-99.87 \%$. The specific energy consumption at the highest operating feed pressure of $980 \mathrm{kPa}$ was determined to be $4.78 \mathrm{~kW} \mathrm{~h} / \mathrm{m}^{3}$. Such comparative study may be useful to select a suitable module and a set of optimum operating conditions to achieve a desired quantity and quality of permeate flux.

Acknowledgments The authors are thankful to Dr. V. S. Patel, Sophisticated Instrumentation Centre for Applied Research and Testing (SICART), Vallabh Vidyanagar, Gujarat, and Dr. N. H. Khan of Central Salt and Marine Chemicals Research Institute (CSMCRI), Bhavnagar, for their valuable help.

\section{References}

(APHA) American Public Health Association (2005) Standard methods for the examination of water and waste-water. In: Clesceri LS, Greenberg AE, Eaton AD, (eds). Washington, D.C. ISBN 0-8755-3047-8

Al-Aseeri M, Bu-Ali Q, Haji S, Al-Bastaki N (2007) Removal of Acid Red and sodium chloride mixtures from aqueous solutions using nanofiltration. Desalination 206:407-413

Alcaina-Miranda MI, Barredo-Damas S, Bes-Pia A, Iborra-Clar MI, Iborra-Clar A, Mendoza-Roca JA (2009) Nanofiltration as a final step towards textile wastewater reclamation. Desalination 240:290-297

Allegre C, Moulin P, Maisseu M, Charbit F (2004) Savings and reuse of salts and water present in dye house effluents. Desalination 162:13-22

Avlonitis SA, Poulios I, Sotiriou D, Pappas M, Moutesidis K (2008) Simulated cotton dye effluents treatment and reuse by nanofiltration. Desalination 221:259-267

Braghetta A, DiGiano FA, Ball WP (1997) Nanofiltration of natural organic matter: $\mathrm{pH}$ and ionic strength effects. J Environ Eng ASCE 123:628

BTTG (1999). Report 5: waste minimization and best practice, British Textile Technology Group, http://www.e4s.org.uk/textile sonline/content/6library/fr_library.htm

Chakraborty S, Bag BC, Dasgupta S, De S, Basu JK (2003) Separation and fractionation of dye solution by nanofiltration. Sep Sci Technol 38:219-235
Erswell A, Brouckaert CJ, Buckley CA (1988) The reuse of reactive dye liquors using charged ultrafiltration membrane technology. Desalination 70:157-167

Forgacs E, Cserhati T, Oros G (2004) Removal of synthetic dyes from wastewaters: a review. Environ Int 30:953-971

García-Molina V, Lyko S, Esplugas S, Wintgens Th, Melin Th (2006) Ultrafiltration of aqueous solutions containing organic polymers. Desalination 189:110-118

Goodman GA, Porter JJ (1980) Water quality requirements for reuse in textile dyeing processes. Am Dyest Rep 69:33-38

Hamlin JD, Phillips DAS, Whiting A (1999) UV-visible spectroscopic studies of the effects of common salt and urea upon reactive dye solutions. Dyes Pigm 41:137-142

He Y, Li GM, Wang H, Jiang Z-W, Zhao J-F, Su H-X, Huang Q-Y (2009) Experimental study on the rejection of salt and dye with cellulose acetate nanofiltration membrane. J Taiwan Inst Chem Eng 40:289-295

Jiraratananon R, Sungpet A, Luangsowan P (2000) Performance evaluation of nanofiltration membranes for treatment of effluents containing reactive dye and salt. Desalination 130:177-183

Koyuncu I, Topacik D (2002) Effect of organic ion on the separation of salts by nanofiltration membranes. J Membr Sci 195:247-263

Koyuncu I, Topacik D, Yuksel E (2004) Reuse of reactive dyehouse wastewater by nanofiltration: process water quality and economical implications. Sep Purif Technol 36:77-85

Levenstein R, Hasson D, Semiat R (1996) Utilisation of the Donnan effect for improving electrolyte separation with nanofiltration membranes. J Mem Sci 116:77-92

Maheswari GP, Al-Ramadhan M, Al-Abdulhadi M (1995) Energy requirement of water production in dual-purpose plants. Desalination 101:133-140

Mo JH, Lee YH, Kim J, Jeong JY, Jegal J (2008) Treatment of dye aqueous solutions using nanofiltration polyamide composite membranes for the dye wastewater reuse. Dyes Pigm 76:429-434

Nataraj SK, Hosamani KM, Aminabhavi TM (2009) Nanofiltration and reverse osmosis thin film composite membrane module for the removal of dye and salts from the simulated mixtures. Desalination 249:12-17

Pastagia KM, Chakraborty S, DasGupta S, Basu JK, De S (2003) Prediction of permeate flux and concentration of two-component dye mixture in batch nanofiltration. J Membr Sci 218:195-210

Rai U, Guha BK, Kumar J (2000) Treatment of distillery waste water using membrane filtration for water reuse. In: Proceedings of Indian Chemical Engineering Congress, vol 2, WTR 17-20

Satyanarayana SV, Bhattacharya PK, De S (2000) Flux decline during ultrafiltration of kraft black liquor using different flow modules: a comparative study. Sep Purif Technol 20:155-167

Scholz W, Lucas M (2003) Techno-economic evaluation of membrane filtration for the recovery and re-use of tanning chemicals. Water Res 37:1859-1867

Uzal N, Yilmaz L, Yetis U (2010) Nanofiltration and reverse osmosis for reuse of indigo dye rinsing waters. Sep Sci Tech 45:331-338

Van der Bruggen B, Daems B, Wilms D, Vandecasteele C (2001) Mechanisms of retention and flux decline for the nanofiltration of dye baths from textile industry. Sep Purif Technol 22-23:519-528

Yeung KW, Shang SM (1999) The influence of metal ions on the aggregation and hydrophobicity of dyes in solutions. J Soc Dyers Colour 115:228-232

Yu S, Liu M, Ma M, Qi M, Lü Z, Gao C (2010) Impacts of membrane properties on reactive dye removal from dye/salt mixtures by asymmetric cellulose acetate and composite polyamide nanofiltration membranes. J Membr Sci 350:83-91

Zularisam AW, Ismail AF, Salim MR, Sakinah M, Ozaki H (2007) The effects of natural organic matter (NOM) fractions on fouling characteristics and flux recovery of ultrafiltration membranes. Desalination 212:191-208 